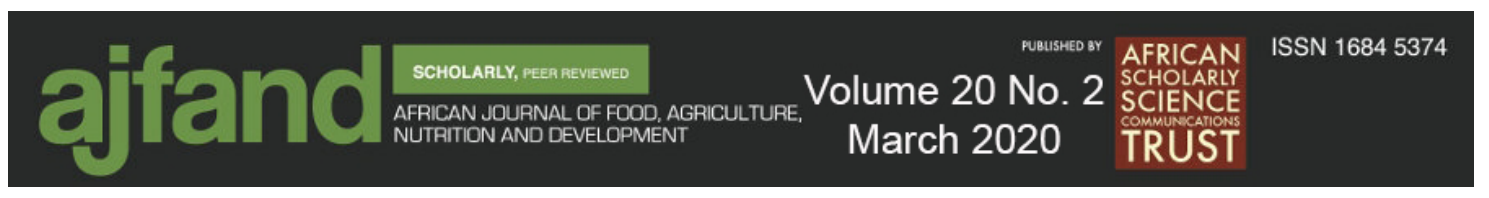

Afr. J. Food Agric. Nutr. Dev. 2020; 20(2): 15431-15454

DOI: 10.18697/ajfand.90.18455

\title{
IMPACT OF INTEGRATED FRUIT FLY MANAGEMENT STRATEGY ON FOOD SECURITY AMONG SMALLHOLDER MANGO FARMERS IN KENYA
}

\section{Nyang'au PN ${ }^{1,2}$, Muriithi BW ${ }^{2 *}$, Nzuma JM'1, Irungu $\mathrm{P}^{1}$, Gichungi $\mathrm{HM}^{\mathbf{1}}$ and $\mathrm{G}$ Diiro ${ }^{2}$}

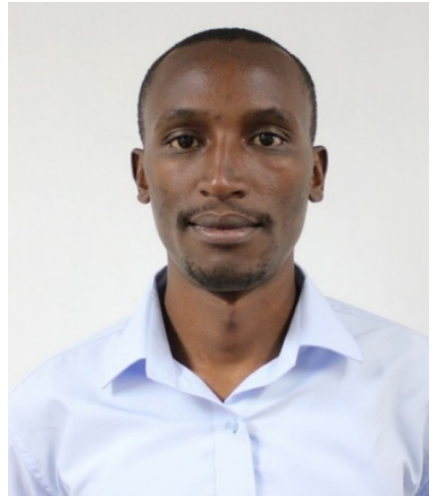

Paul Nyang'au

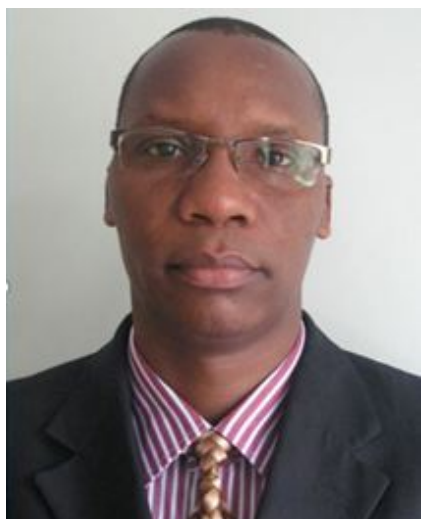

Patrick Irungu

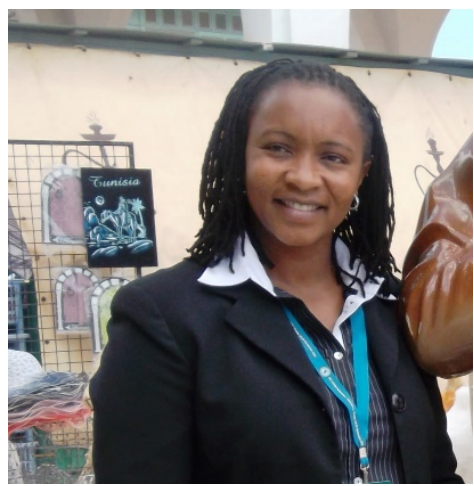

Beatrice W. Muriithi

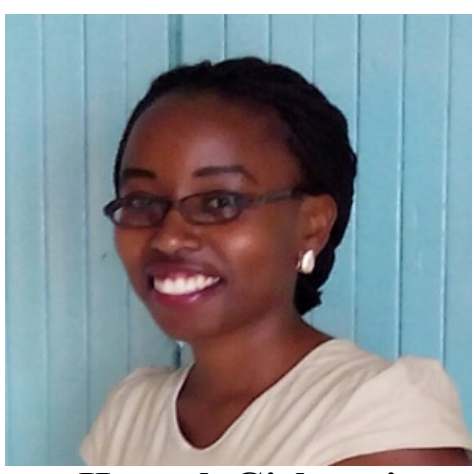

Hannah Gichungi

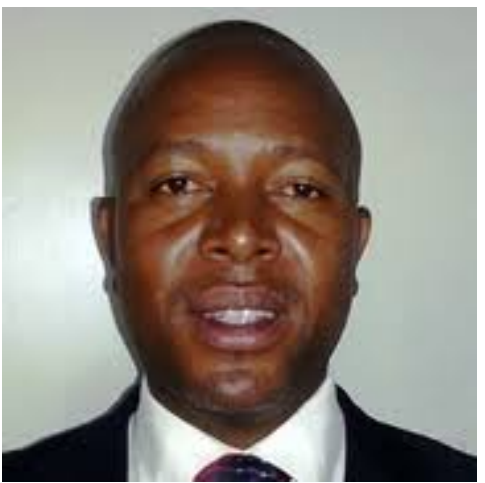

Jonathan Makau Nzuma

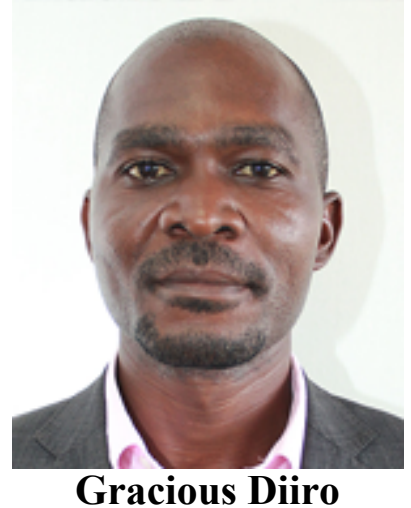

*Corresponding author email: bmuriithi@icipe.org

${ }^{1}$ Department of Agricultural Economics, University of Nairobi, PO Box 29053, Nairobi, Kenya

${ }^{2}$ International Centre of Insect Physiology and Ecology (icipe), PO Box 30772-00100, Nairobi, Kenya 


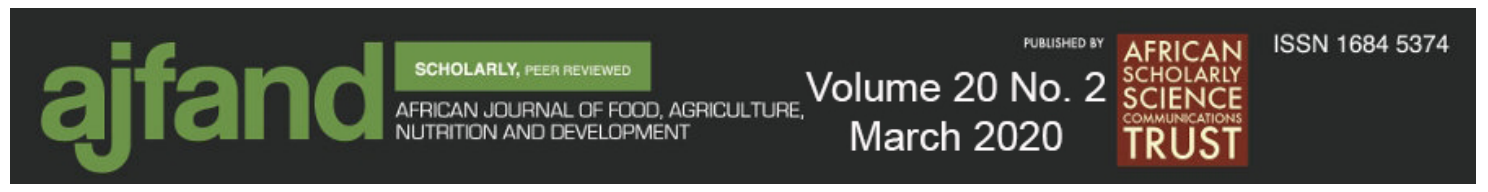

\begin{abstract}
Adoption of agricultural innovations is perceived as a key avenue for poverty reduction and improved food and nutritional security in developing countries. The International Centre for Insect Physiology and Ecology (icipe) has developed and implemented a set of Integrated Pest Management (IPM) strategies in several sub-Saharan African countries aimed at controlling mango infesting fruit flies (Bactrocera dorsalis). Although positive returns from the use of fruit fly IPM have already been documented, the impact of these technologies on food security is not well understood. This study evaluated the impact of the IPM strategy on food security with the help of a two-wave panel household survey data collected in Machakos County in Kenya. A difference-in-difference model was fitted to the data of a randomly selected sample of 600 mango growing households. A seven-day recall was used to elicit per capita calorie intake, while a 30-day recall was used to measure household dietary diversity. A before-and-after intervention and withand-without (treatment and control) study design was utilized. The regression estimates indicate that fruit fly IPM use had a positive impact on per capita calorie intake but no significant effect on Household Dietary Diversity Index (HDDI) in comparison with the IPM non-users. This suggests that farmers using the fruit fly IPM technology benefit from income gains, and higher incomes improve the quantity of food consumed but not the diversity of the foods. This could be explained by a large share of the expenditure on food that was devoted to cereal staples such as maize, wheat, and rice as reported during the qualitative study. Other factors that had an effect on per capita calorie include the level of farm income, access to the extension services, wealth category and distance to agricultural input market and household size. This study recommends wider dissemination and upscaling of the fruit fly IPM strategy in mango producing regions to facilitate broader impacts on household-level food security.
\end{abstract}

Key words: Integrated pest management IPM, Difference-in-difference, Food security, Kenya, Africa 


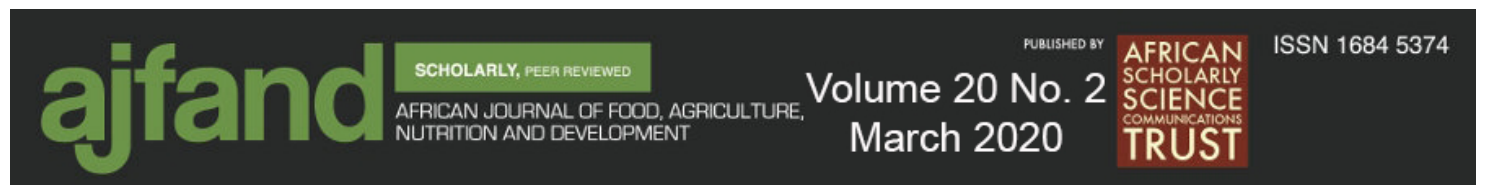

\section{INTRODUCTION}

The horticulture sector in Kenya accounts for about $36 \%$ of agricultural GDP and grows between 15 and $20 \%$ a year [1]. Out of the various tropical fruits grown in Kenya, mangoes are leading the market share in both local and export markets [2]. In Kenya, mangoes are ranked third after bananas and pineapples in terms of acreage and total production volumes among the tropical fruits sub-section [3]. Mango production provides employment to many people to both the rural and urban areas who depend on seasonal labor demands and accounts for $26 \%$ of fruit exports [2]. According to Horticulture Validated report 2014, mangoes earned Kenya US\$89 million/ year. Major destinations for export mangoes from Kenya include the United Arab Emirates (53\%), Tanzania (20\%), and Saudi Arabia (22\%) [4].

However, the current mango production is far below its potential. The sub-sector is faced with a myriad of challenges, including high perishability nature of the fruit, inadequate clean and quality planting materials, pests and diseases infestation, high cost of inputs, limited adoption of improved technologies, seasonal gluts, poor post-harvest handling techniques, and poor market infrastructure [5]. Among these challenges, insect pests and diseases are ranked highest [6]. Directly pests and diseases lower the quantity and quality of the mango produce, while indirectly quarantine restrictions on mangoes infested by fruit-flies limit access to lucrative export markets abroad [7].

Chemical broad-spectrum pesticides are used as the sole method of pest control by mango farmers in Kenya [8]. The use of chemical pesticides, however, has been unsuccessful against controlling some insect pests hence farmers tend to increase the frequency of spraying or mix different pesticides to upsurge pest control [9]. In order to reduce losses in mangoes due to fruit flies ( $B$ dorsalis), cut down the cost of production, increase producers' income and improve market access to quality mangoes, the International Center for Insect Physiology and Ecology (icipe) and partners have developed an Integrated Pest Management (IPM) strategy which is being promoted across several countries in Africa.

The strategy is a combination of different interventions working together rather than a single management strategy [10 - 12]. It comprises baiting and male annihilation techniques, orchard sanitation, fungal application, use of parasitoids and weaver ant (Oecophylla longinoda). An insecticide (Spinosad) is combined with a proteinous food

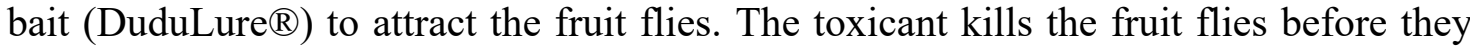
attack the mangoes [13].

The Male Annihilation Technique (MAT) combines malathion (a toxicant) and methyl eugenol (a male attractant) to trap and kill male flies reducing the chances of mating hence lowering the population of fruit flies [10]. The bio-pesticide utilized targets the larva stage and emerging adults of the fruit flies. However, they have no effect on beneficial parasitoids, instead, they complement them in fruit fly suppression [13]. In order to achieve orchard sanitation, a tent-like structure referred to as an augmentorium is used. It suppresses any emerging fruit flies from rotten fruits deposited in the structure 


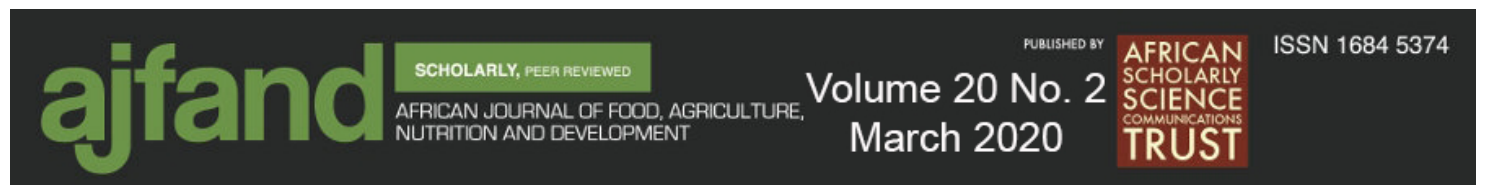

as well as conserving their biological enemies (parasitoids) by allowing them to escape from the augmentorium [14].

In Kenya, the strategy has been implemented in the major mango growing areas of Eastern and Coast counties. Trials on the IPM strategy were conducted at Mwala subcounty in 2015 through one of the icipe's project where farmers were enrolled and trained on the use of the mango fruit fly IPM package components at designated lead mango orchards. The technologies aim to lower the cost of production and reduce mango losses induced by fruit flies [12].

In recent years, many studies have been conducted in developing countries analyzing the impact of agricultural technologies on poverty, hunger and malnutrition reduction. The studies by Asfaw et al. [15] and Mulugeta et al. [16] have shown that agricultural innovations have positive effects on-farm productivity, income, food security, and poverty reduction among adopters. The current mango fruit fly IPM strategy promotion and dissemination activities have shown success with many farmers taking up the strategy $[11,12,17]$.

These studies further show that the use of fruit fly IPM strategy can lead to a reduction in mango losses due to fruit fly invasion, reduce expenditure on insecticide and increase net income. The study by Fernandez-Cornejo [18] has demonstrated positive impacts of IPM technologies household livelihoods and the environment. Since the introduction of the IPM strategy in Kenya, no research has been done to evaluate the intervention in terms of its effects on household-level food security. The current study seeks to fill this gap by assessing the impact of the fruit fly IPM strategy on household food security among mango growers using the case of one of the program's action sites in Kenya.

Using two rounds of panel data obtained from smallholder mango farmers in Machakos County, this study contributes to the literature on the impact of IPM technologies on rural livelihoods. Specifically, the current study examines whether fruit fly IPM adopters are better off than non-adopters in terms of household food security. On one hand, the innovations may lead to an increase in marketable produce or save labour for non-farm activities and subsequently increase household income and food security. It is also possible that an increase in income generated through the innovation may not be utilized to buy food these interventions may not yield the expected results, hence, no effect on household food security [19].

The current study employs a difference-in-difference estimator to analyze the impacts of the intervention on food security. To capture the two pillars of food security (food availability and accessibility), a seven-day recall is used to elicit per capita calorie intake while a 30-day recall is used to measure household dietary diversity index. The rest of the paper is organized as follows. The next section presents the conceptual framework adopted by this study. Section 3, describes the methodology which includes the study area and sampling techniques, measurement of food security and empirical approaches. Section 4 presents descriptive statistics, empirical results, and discussion. The last section summarizes and concludes the paper. 


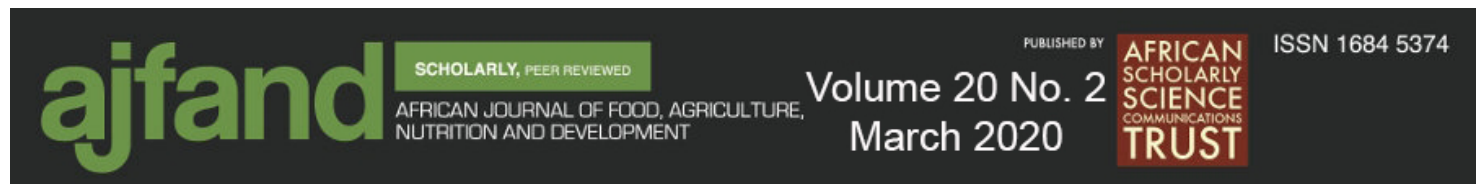

\section{MATERIALS AND METHODS}

\section{Study area and sampling technique}

The data were collected before and after and with and without fruit fly IPM intervention (Analogously referred to treatment and control groups) in Machakos county, which is among the leading mango producing areas in Kenya. The climatic factors in the study area have a greater bearing on mango production. The two-stage sampling procedure was followed to select the sample of mango growers. The first stage involved selecting two sub-counties in Machakos county (Namely Kangundo and Mwala), where mango production is predominant (Figure 1). A sampling frame comprising all mango farmers in the selected areas was then compiled with the support of the sub-county agricultural officers.

From this list, following the standard procedure outlined by Bartlett et al. [22], the final sample size was computed. Three hundred households were randomly selected from the treatment area (Mwala sub-county) and similar sample size from the control group (Kangundo sub-county). To reduce location biases in the analysis, both the treatment and control groups have the same average climatic and market potential. In addition, in order to minimize any potential interregional spillover effects of the IPM technology benefits, the selected control site was about $30 \mathrm{~km}$ away from the treatment area.

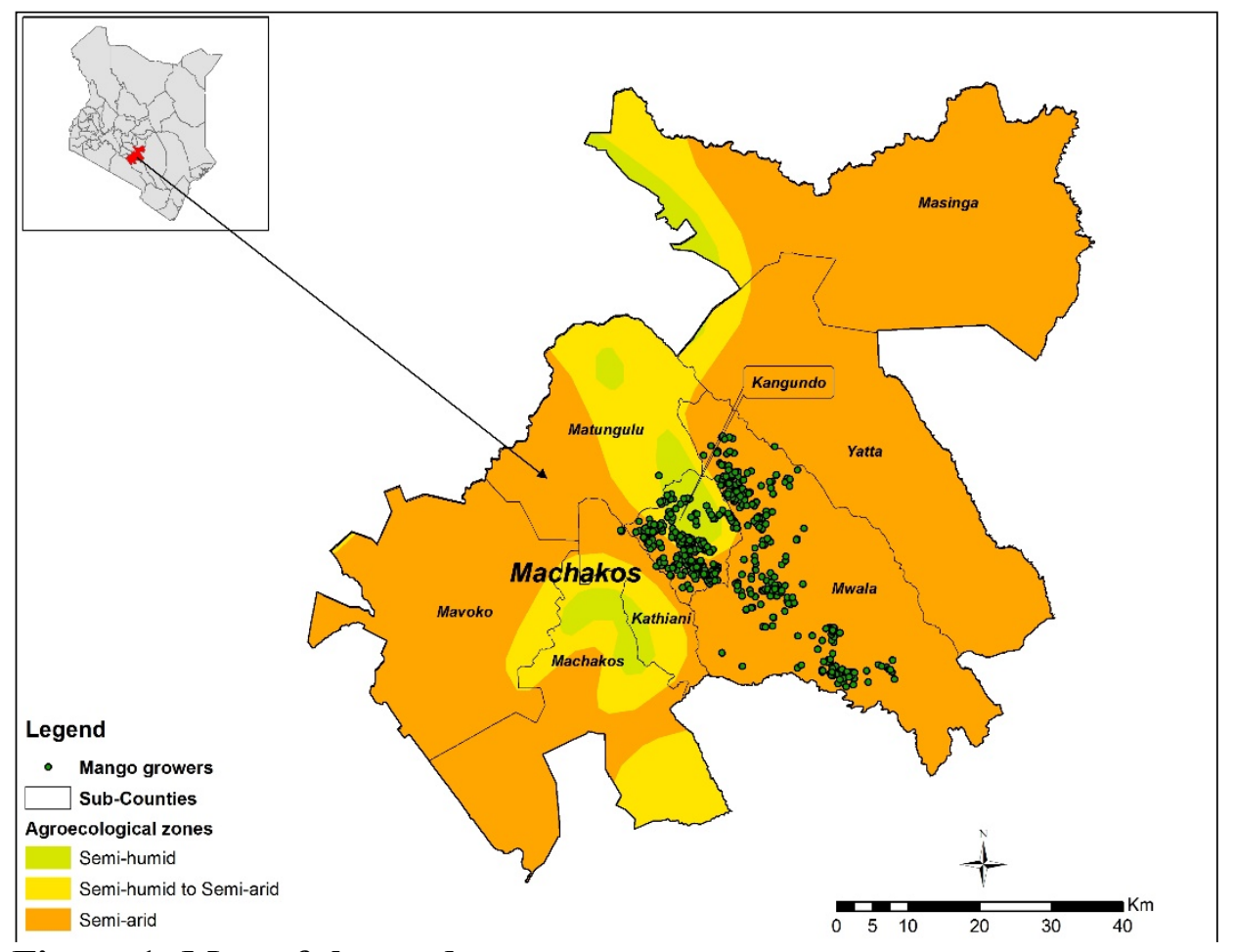

Figure 1: Map of the study area

The data were collected using a pre-tested semi-structured questionnaire. Information on farmers' socio-economic characteristics, mango production and marketing and food security indicators, as well as other contextual data, were collected. The household heads or spouses were interviewed as they are the main decision-makers in agriculture. An 


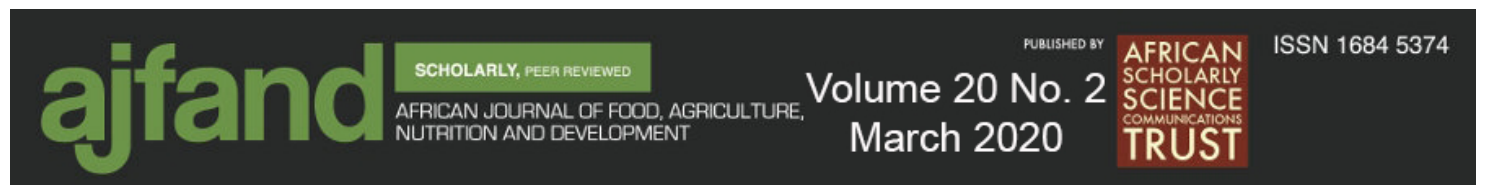

initial (baseline) survey was undertaken in both study sites in February and March 2015 to collect baseline information on the 600 households on mango production during the May 2013-April 2014 growing season.

Upon completion of the baseline survey, farmers in Mwala sub-county were trained on how to apply the IPM technology on their mango orchards and given the various components of the technology. A follow-up survey targeting the same households was undertaken in December 2015 to capture information on IPM technology used during the May 2014-April 2015 mango season. During this follow-up survey, 4\% of the 600 households could not be interviewed because they could either not be traced or had moved away from their homesteads. The analysis of this study subsequently utilized the balanced sample of 566 households, out of which 289 were from the treatment site (Mwala sub-county) and 277 from the control site (Kangundo sub-county).

\section{Conceptualizing mango production, fruit fly IPM, and food security nutrition inter- linkages}

The effect of fruit fly IPM technology on household food security is diffused through four main linkages; (i) introduction of the technology, (ii) adoption of the technology in a farming system, (iii) reallocation of farm resources between enterprises as a result of technology adoption, and (iv) changes in food consumption patterns as a result of changes in income derived from the proceeds of technology adoption borrowing from von Braun [20].

The introduction of an agricultural sector intervention or technology results in possible increases in agricultural income, which includes income from crops produced and sold, that could allow greater household expenditures on food and could result in greater overall food consumption and an improvement in household food and nutrition security [21]. Higher agricultural income might also result in higher non-food expenditure, including spending on health care, which could improve a household's nutrition outcomes. Moreover; rising incomes may contribute to better dietary quality and higher demand for more nutritious foods, including vegetables, fruits, and animal products.

The principal objective of the IPM strategy is to provide farmers with new opportunities to improve their livelihood. In mango production, for example, this is achieved through reduced farm level mango loss, reduced insecticide usage and enhanced quality of mangoes supplied to the market. The use IPM strategy may also raise the overall mango productivity by boosting effectively other input use. Ceteris paribus, these effects raise farmers' profit leading to improved welfare measures such as food security, poverty reduction, and general wellbeing.

The current study explores the role of IPM technologies for mango fruit fly control in influencing intermediate indicators along with linkages connecting agriculture to food security outcomes. Specifically, this study explores whether and to what extent the adoption of these technologies by smallholder mango farmers affects household-level food security indicators (food availability and accessibility). 


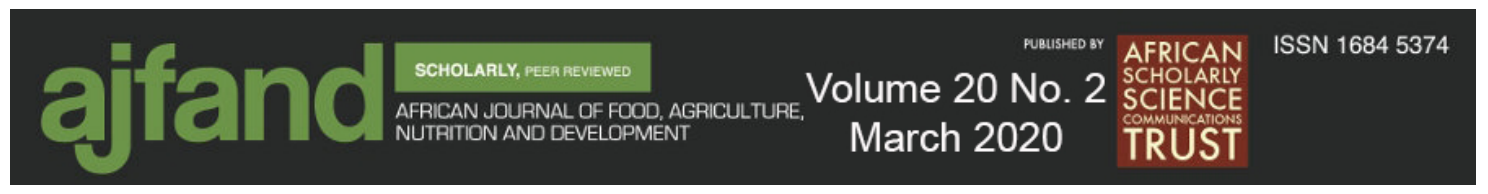

The current study tests the hypotheses that, ceteris peribus, smallholder mango farmers that use IPM technologies into their production system have: (i) more food availability as measured by calories consumed, and (ii) more access to food, measured by (Household Dietary Diversity Index [HDDI]). These outcomes may occur because of increase in agricultural income. The empirical approach on how to assess the impact of IPM is presented below.

\section{Measuring food security}

Food security is a broad concept that is generally defined as physical and economic access to adequate, safe and nutritious food by all people at all times for an active and healthy life [23]. The broad definition implies that food security is more than food production and accessibility. Generally, this definition has four dimensions that constitute the four pillars of food security: food access, availability, utilization and stability of food supply [24]. While food security encompasses the four dimensions, the time and cost involved in collecting data on all the dimensions may be prohibitively high. This is evident from previous studies, where different researchers adopt different measures of food security. For instance, Babatunde et al. [25] suggests objective food security measures including calorie intake and food expenditure data. On the other hand, Pinstrup-Andersen [26] proposed use of total household income and food prices to estimate food security, while Kassie et al. [27] used respondent's self-assessment food security status over a period of twelve months prior to the survey and categorized such status in four categories - food shortage throughout the year (chronic food insecurity), occasional food insecurity (Transitory food insecurity), no food shortage but no surplus (break-even) or food surplus.

In this study, the food security situation is measured using two components: (i) Household per capita calorie intake and (ii) Household Dietary Diversity Index (HDDI) according to Swindale and Bilinsky study [28]. This was done using 30-days and 7-days recall data, respectively. Household per capita calorie intake is defined as the amount of food available for consumption per adult equivalent per day measured in kilocalories [16]. Using the formulae below, the household's energy consumption levels were calculated [28]:

$$
C_{i}=\Sigma_{1}^{n} W_{j} B_{j}
$$

where $\mathrm{C}_{\mathrm{i}}$ is the total calorie intake for household $\mathrm{i}, \mathrm{W}_{\mathrm{j}}$ is the weight in grams of intake of food commodity $\mathrm{j}, \mathrm{B}_{\mathrm{j}}$ is the standardized food energy content of the $j$ th food commodity (from nutrient conversion table). Following Mulugeta and Hundei [16], $\mathrm{C}_{\mathrm{i}}$ was divided by the household's total adult equivalent to get the per capita calorie intake. Based on the average dietary energy requirement in Kenya, the current study uses a minimum intake of $2250 \mathrm{kcal}$ per adult equivalent and categorizes households below this threshold as undernourished.

Dietary diversity is a food security outcome (Access) measured mainly at the individual or household level. It has also been useful in providing food availability information in society and shows seasonal dietary pattern changes. The sum of a number of food groups 


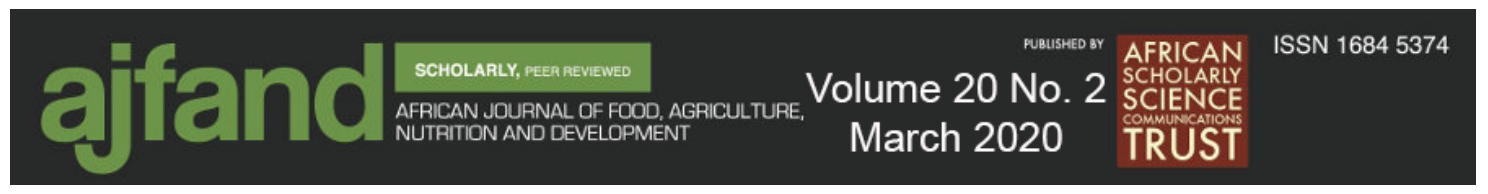

consumed over a reference period is used to calculate the dietary diversity index [29]. The household dietary diversity index was developed by calculating a simple count of the sum of the different number of food types consumed in the previous day, following the United Nations Food and Agriculture Organization (FAO) food groups which include: Cereals, root and tubers, pulses/legumes, vegetables, milk and milk products, eggs, meat, oil/fats, sugar/honey, fruits, fish and seafood and miscellaneous [28].

\section{Empirical approach}

The effect of fruit fly IPM strategy on food security was estimated using the Differencein-Difference (DiD) method. The method combines both with-and-without before and after adopting the technology to estimate the difference between the observed mean outcomes for the treatment (with) and the control (without) groups before and after the technology intervention. The DiD model compares outcome changes over time and also accounts for selection bias [30]. To assess the impact of the fruit fly IPM technology on food security, the unconditional treatment effect was expressed as follows:

$$
Y_{i}=\alpha+\gamma t_{i}+\delta C_{i}+\tau C_{i} * t_{i}+\varepsilon_{i}
$$

where $Y_{i}$ is the outcome of interest for farmer $i$, in this case, food security parameter (Per capita calorie intake, or HDDI); $C_{i}$ is a dummy variable, given as 1 if farmer $i$ is in the treatment group and 0 if in control group; $t_{i}$ a dummy variable, defined as 1 if in posttreatment period (follow-up survey), and 0 if in pre-treatment (Baseline) period. The actual treatment variable which measures the impact of the fruit fly IPM strategy on food security outcomes is represented by the interaction in term of treatment and time, $C_{i} * t_{i}$. The coefficient of the interaction is $\tau$. The coefficient for the time dummy, $\gamma$, capture the changes that occur over time that are independent of the fruit fly IPM strategy, while the strategy coefficient $\delta$, captures the initial average differences between the treatment and control groups.

The unconditional treatment effect of DiD expressed in Eq. (2) assumes that food security is only affected by the intervention, while other factors do not change across time [31]. However, this is not realistic as farm and household conditions are expected to vary and may also affect the outcome of interest [31]. Therefore, the estimated conditional treatment effect of $\mathrm{DiD}$ as follows:

$$
Y_{i}=\alpha+\gamma t_{i}+\delta C_{i}+\tau C_{i} * t_{i}+\lambda_{i} \boldsymbol{X}_{i}+\varepsilon_{i}
$$

where $\boldsymbol{X}_{i}$ represents a set of household and farm characteristics that might affect the food security parameters.

The independent variables chosen for the above empirical model are based on previous empirical review on technology adoption and food security interlinkage studies presented below. Table 1 presents the descriptions and expected signs of the variables used in the model. The age of the household head impacts his or her ability to supply labour for food production. The square of age is included in the model as a result of the nonlinear 


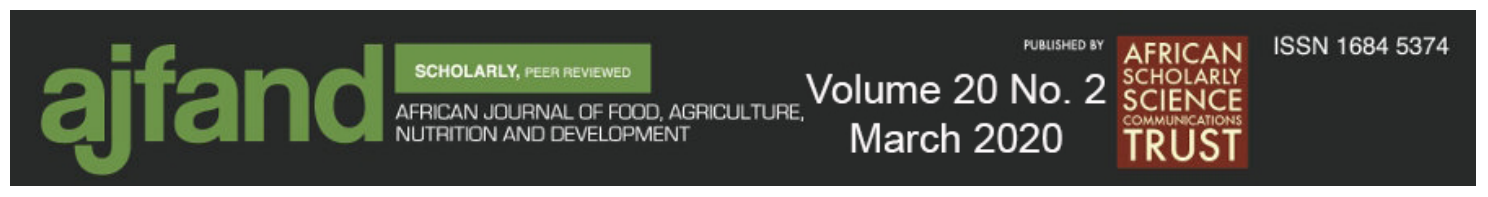

relationship between age and food security. The education level of the household head determines the number of opportunities available to enhance livelihood strategies, improve food security and reduce poverty levels [32]. With regard to gender of household head, male-headed households have been found to be more food secure compared to female-headed households who have limited access to productive resources [27].

The household size determines the amount of labor available for farm production, farm produce kept for own consumption and agricultural marketable surplus of farm harvest [32]. Households with large family members are mostly associated with a high dependency ratio and more food requirements, depicting a negative effect on food security. However, an increase in household size could translate into an increase in the number of income-earning adults depicting a positive effect on food security [33]. Therefore, the expected sign for household size is indeterminate.

Household heads with many years of mango farming activities are expected to increase their ability to diversify production hence reduce the food shortage risk. The years of farming experience may also influence the adoption of improved agricultural technologies by rural households. A research finding by Feleke et al. [34] finds a positive relationship between farming experience and food security. Credit availability is also mentioned in food security literature, as households could obtain it either in cash or inkind for either consumption or production [16].

Social capital and networks, in this study, captured using group membership, act as a means to access information and exchange food price information, subsequently reducing food security among rural communities. Extension contact is one source of information for many rural farmers through field officers. Field extension officers also play an important role in the dissemination of new technologies in food production. This study captures extension with a value of 1 if the farmer was contacted by an extension agent for the last twelve months prior to the survey. Distance to the nearest market was also considered as an additional proxy for information access. The probability of being food secure decreases with greater distance to the market. Improving access to markets is likely to impact positively on productivity and food security.

As a measure of the wealth of a household, we include the total assets owned. In addition, we computed a wealth index using Principal Component Analysis (PCA) based on the number of assets owned by a household. Households were then grouped into three different wealth categories- $2=$ Wealthy $1=$ Moderate wealthy $0=$ Poor/not wealthy. Households with greater incomes and resources tend to have more diverse diets. A household wealth index was derived.

The DiD estimator for per capita calorie intake $\left(\mathrm{Y}_{\mathrm{i}}\right)$, a continuous covariate, was estimated with Ordinary Least Squares (OLS). OLS produces Best Linear Unbiased Estimators (BLUE) of the coefficients given that sum errors have an expectation of zero and are uncorrelated and have equal variances. Eq. (4) below specifies the conditional model used in assessing the impact of fruit fly IPM on per capita calorie intake. 


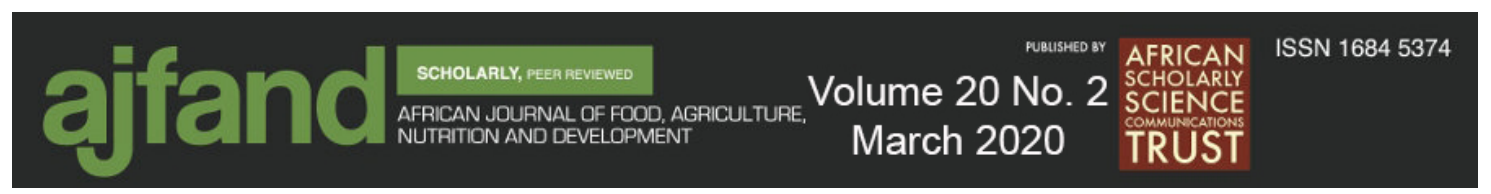

$$
\begin{aligned}
& Y_{i}=\alpha+\gamma(\text { Time })+\delta(I P M)+\tau(\text { Time } * I P M)+\lambda_{1}(\text { Age })+\lambda_{2}(\text { Education })+\lambda_{3}(\text { Gender })+\lambda_{4}(\text { Householdsize }) \\
& +\lambda_{5}(\text { Farmingexperience })+\lambda_{6}(\text { Groupmembership })+\lambda_{7}(\text { Extension })+\lambda_{8}(\text { Assetwealth }) \\
& +\lambda_{9}(\text { Marketdistance })+\lambda_{10}(\text { Credit })+\varepsilon_{i}
\end{aligned}
$$

On the other hand, Poisson regression was estimated to assess the impact of fruit fly IPM on HDDI. The poisson model was chosen because the food security parameter HDDI is a count data variable that is used to measure diet quality. Following Greene's study [35], let $Y i$ denote the number of food groups consumed by the $i$ th household. The empirical specification of this "count" variable is assumed to be random and, in a given time interval (24 hours), has a Poisson distribution with probability density, such that:

$$
P\left(Y_{i}\right)=\frac{e^{-\mu} \mu^{y}}{y !}
$$

where $Y_{i}$ denotes the number of food groups, out of 12, consumed by the ith household $\mathrm{i}=1,2,3 \ldots 12$ and $\mu=E(Y)$ expected index (and variance). The mean $(\mu)$ depends on a vector of explanatory variable (s) X. Since the $\log$ of the expected value of $\mathrm{Y}$ is a linear function of the explanatory variable (s) X. The Model $\log$ of $\mu$ as a function of $X$ :

$$
\boldsymbol{\mu}=e^{\sum_{j=1}^{K} \beta T_{i}+\gamma t_{i}+\delta T_{i} * t_{i}+\lambda_{i} X_{j i}}
$$

Eq. (6) can also be written as follows;

$$
\ln (\mu)=\sum_{j=1}^{K} \beta T_{i}+\gamma t_{i}+\delta T_{i}^{*} t_{i}+\lambda_{i} X_{j i}
$$

Or

$$
\ln (\mu)=\alpha+\beta T_{i}+\gamma t_{i}+\delta T_{i}^{*} t_{i}+\lambda_{i} X_{i}+\ldots+\lambda_{k} X_{k}
$$

Where $\alpha$ is the constant, $\beta, \gamma, \delta$ and $\lambda_{1} \ldots \ldots \lambda_{13}$ are parameters to be estimated and $\mathrm{X}_{1} \ldots \mathrm{X}_{13}$ are the explanatory variables. It should be noted that $\mathrm{Y}>0$ as the number of food groups consumed by a household over the previous 24 -hour period must be strictly positive.

\section{RESULTS AND DISCUSSION}

\section{Descriptive statistics}

Descriptive statistics of variables used in modeling fruit fly IPM participation and food security outcomes from the baseline are presented in Table 2. With respect to demographic characteristics, independent sample $t$-test of mean differences showed that fruit fly IPM participants had household heads with lower age on average, lower level of education but large household sizes. The age of the household heads ranged from 26 to 95 years with an average of 57.5 and 60.5 years for fruit fly IPM participants and non- 


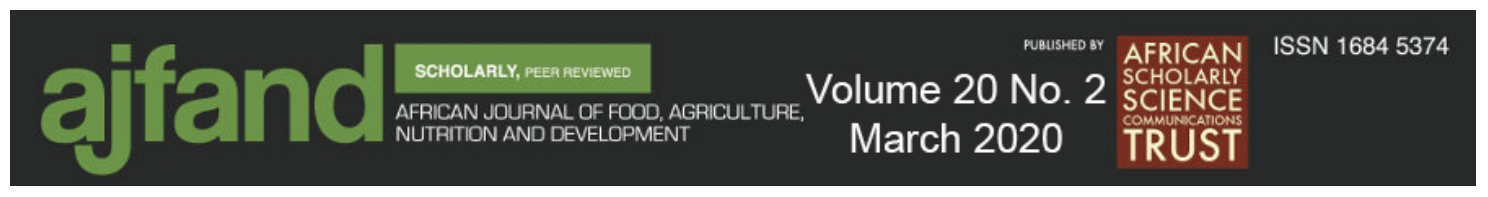

participants respectively. On average, heads of non-participating households had a formal education of about 10.2 years while fruit fly IPM participants reported about 8.6 years.

Fewer households (11\%) among those who were not using the fruit IPM were reported having received extension services on mango farming in the last 12 months, compared to the participants $(24 \%)$. The average household size was 5 people among the sampled groups. The results indicate that on average, IPM non-participants traveled a longer distance $(10.5 \mathrm{~km})$ to the market than users $(5.0 \mathrm{~km})$. More IPM participants than nonparticipants belonged to a farmer group ( $31 \%$ and $24 \%$, respectively).

\section{Food security outcomes}

Table 3 presents the average per capita calorie intake and the household dietary diversity indices for the two study areas across the two-time periods. The result shows that the average per capita intake was higher among the non-fruit fly IPM users (Kangundo subcounty) of about $3007 \mathrm{Kcal}$ and $2843 \mathrm{Kcal}$, while the participants (Mwala sub-county) reported about $2840 \mathrm{Kcal}$ and $2731 \mathrm{Kcal}$ during the baseline and follow-up survey, respectively. This shows that on average both areas were above the required per capita calorie intakes of $2250 \mathrm{Kcal}$ and thus food secure. In contrast, the HDDI results show that fruit fly IPM users had a higher average HDDI of 9.8 and 9.7 compared to non-IPM users with 9.8 and 9.7 during the baseline and follow-up survey respectively.

Figure 2 gives the graphical representations of the percentage of food secure households in Mwala and Kangundo sub-counties based on per capita calorie intake. The results indicate that $72 \%$ and $81 \%$ of households were food secure in Mwala, and Kangundo respectively $(\mathrm{p}<0.05)$. This was based on the recommended per capita calorie intake of $2250 \mathrm{kcal}$ by the Kenya National Bureau of Statistics. On the other hand, $67 \%$ and $75 \%$ of all farmers in Mwala and Kangundo, respectively,were food secure during the follow up $(\mathrm{p}<0.05)$.

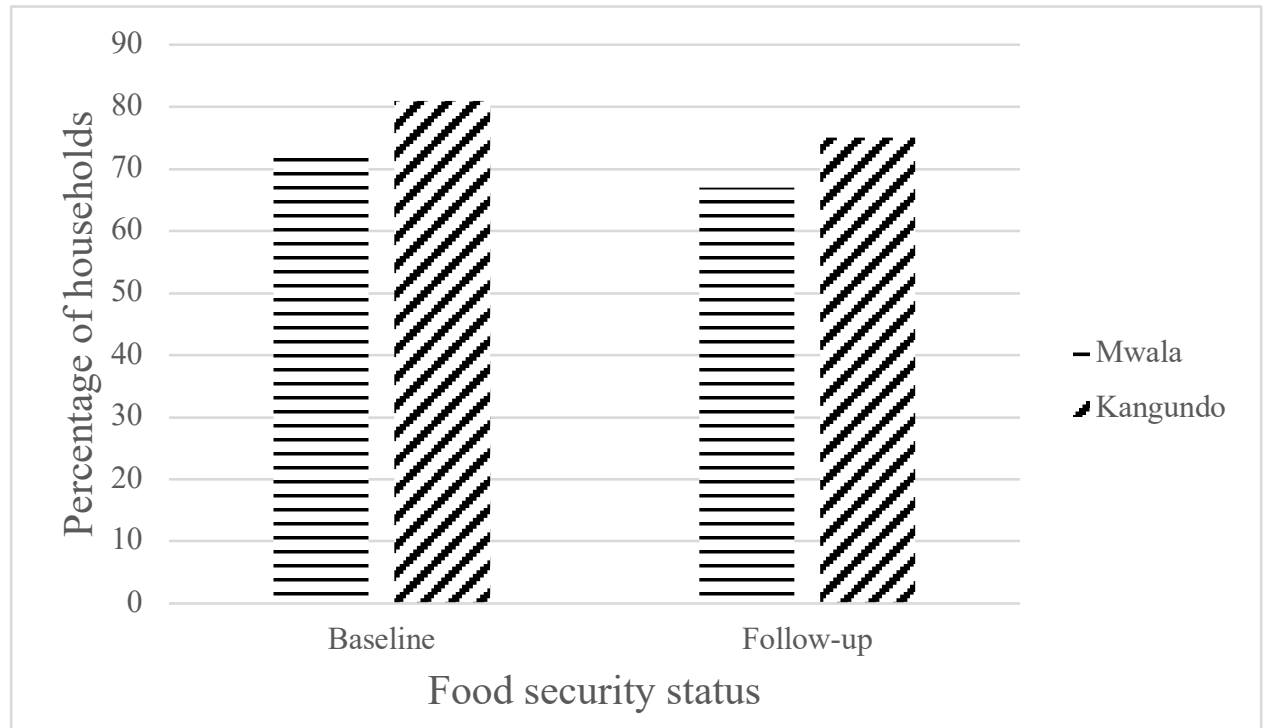

Figure 2: Food security status among fruit fly IPM participants (Mwala subcounty) and Non-participants (Kangundo sub-county) 


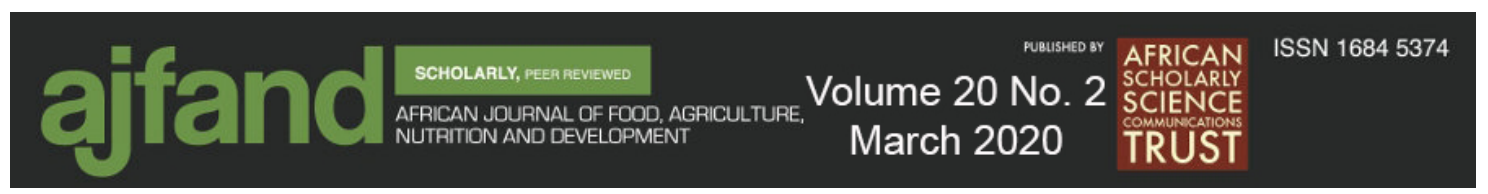

\section{Impact of IPM technology on Per Capita Calorie Intake}

Before estimating the DiD regression model, preliminary tests were carried out. To check for the presence of multicollinearity problem among the independent variables, the Variance Inflation Factor (VIF) was computed. The results of the VIF for the variables included in all the models were less than 10 and the pairwise correlations were less than 0.5 hence no independent variables were dropped from the estimated model. To adjust for autocorrelation, the Iterative Prais-winsten method was used. This procedure recursively estimates the beta coefficients and the error autocorrelation of the specified model until convergence of rho, such as the AR(1) coefficient, is attained [36]. Robust standard errors were used to correct heteroscedasticity.

The results in Table 4 indicate that the difference in calorie intake between the two groups was lower in post-intervention period than baseline. The DiD estimate indicates that on average IPM participants received approximately $1.9 \%$ more per capita calorie intake than the non-participants. This implies that IPM intervention had a positive impact on calorie intake from mango production.

Table 5 reports the estimates derived using the difference-in-difference estimator for the impact of IPM on food security parameters based on the unconditional treatment effect, Eq. (2). Although the coefficient of the unconditional treatment effect of IPM technology is statistically insignificant, the positive sign associated with this coefficient illustrates that participants had an increase in calorie intake than the non-participants. This result should be interpreted with care; as we assume that change in per capita calorie intake is only affected by the intervention (mango fruit fly IPM).

The coefficient of the conditional treatment effect of IPM (Interaction, IPM*time) is positive and statistically significant after controlling for other exogenous factors that may influence the level of household food security. This implies that per capita calorie intake increased for those who used fruit fly IPM strategy in comparison with those who did not $^{1}$.

With respect to the exogenous variables included in Table 6 that are likely to influence the per calorie intake, farm income, access to extension services, wealth category and distance to agricultural input market were positive and significant, while household size exhibited a negative and significant effect. One additional member of a household was associated with $171 \mathrm{Kcal}$ decline in the household per capita intake. This is plausible since households with large family members are mostly associated with a high dependency ratio and more food requirements, depicting a negative effect on food security. The results were consistent with findings by Goshu et al. [37] who found that increase in household size was negatively related to food security.

\footnotetext{
${ }^{1}$ Following Tambo and Wünscher [19], the authors attempted other food security outcomes including food consumption expenditure, food gap and household hunger scale. However, our results revealed that fruit fly IPM strategy do not significantly enhance the three outcomes of food security stated above. The results are available from the authors upon request
} 


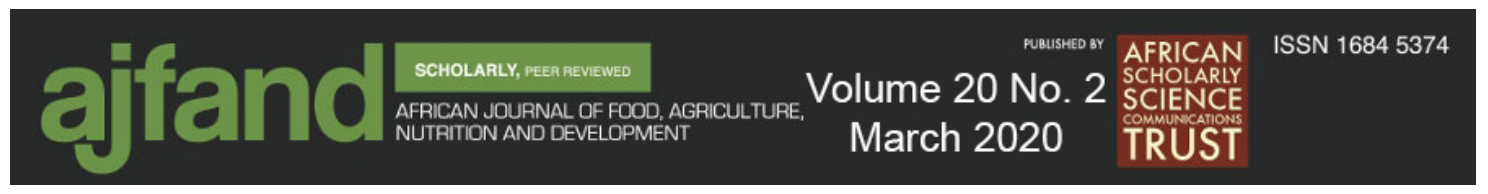

Contrary to the a priori expectation, the results indicate that all factors held constant, an additional increase in agricultural market distance increases calorie intake by $14 \mathrm{Kcal}$. These results were inconsistent with most of the available literature [27, 34], which suggests that food security is negatively related to market distance. Households that accessed agricultural extension were found to be consuming $164 \mathrm{Kcal}$ more other factors held constant. Households that belonged in the moderate wealthy category compared to those not wealthy, with all other variables held constant resulted to $166 \mathrm{Kcal}$ increase in the household per capita calorie intake. Similarly, belonging to a wealthy category compared to moderate wealthy also resulted to an increase of $188 \mathrm{Kcal}$ in the household's per capita calorie intake.

\section{Impact of IPM technology on HDDI}

Table 6 presents the results of the average fruit fly IPM technology effect on HDDI between IPM participants and non-participants across the two-time periods. The results showed that the two groups did not differ significantly in terms of HDDI both in the baseline and follow up. The Difference-in- Differences (DiD) estimate indicates a 0\% increase in HDDI for the two groups (Table 6). This could be explained by the fact that the household dietary diversity behavior adjusted only slightly because income was subjected to temporal variability. Thus, the increased food consumption reported earlier is related to availability, and not diversity of food. In fact, the focused group discussions indicated that a large share of the expenditure on food was devoted to cereal staples such as maize, wheat, and rice. Although not statistically significant, the coefficient presented in Table 7 tends to suggest that IPM technology led to an increase in HDDI levels of the participants.

The marginal effects from the truncated Poisson regression show that the major factors influencing HDDI include: household head's years of formal education, years of farming experience, farm income, number of livestock owned, and wealth category (Table 7). Household head's years of formal education is positively related to access to food as measured by HDDI and is significant at the 5\% level. A higher education level is associated with a Ounit increase in the household's access to food all other variables held constant. Given that the average years of schooling is 9 years, with most farmers completing primary education, this finding implies that with this level of literacy most households are likely to diversify their food.

The marginal effect of the total livestock owned has a positive sign and is significant at $1 \%$ level implying that an additional increase in livestock increases households' HDDI by 0units. Livestock act as a source of food, for instance, milk, eggs, and meat hence households with more livestock units are likely to access more food. Farm income was found to positively influence a household's HDDI, where a $1 \%$ increase in income increased HDDI by Ounits all other factors held constant. Increase in farm income improves economic food access especially to households previously undernourished. Also, higher incomes may result in better dietary quality and increased demand for more nutritious foods. Movement from moderate wealth to a wealthy category was found to increase the HDDI by 0.2 units all else held constant. 


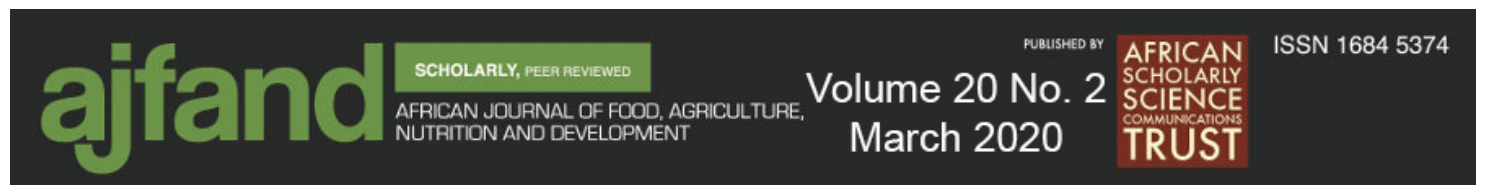

\section{CONCLUSION}

The aim of this study was to assess the impact of an integrated pest management strategy for the suppression of mango fruit flies on food security among smallholders in Machakos County, Kenya. The results indicate that fruit fly IPM users had a positive impact on per capita calorie intake but no significant effect on Household Dietary Diversity Index (HDDI) compared with the IPM non-users. The level of farm income, access to extension services, wealth category and distance to agricultural input market and household size were other factors that had an effect on per capita calorie. The empirical findings of this study suggest that promoting IPM technology is likely to benefit farmers, especially smallholder farmers to improve their food consumption levels (per capita calorie intake). Hence, developing countries should invest more in such technologies to reduce food insecurity. Furthermore, the findings from this study reveal that distance to nearest agricultural input market, household size, access to relevant information and the diverse financial status of farmers should be considered in the design and implementation of workable food security policies. Thus, those policies should go beyond food availability, and also focus on nutrition security in the study region.

One of the shortcomings of our study is the short span of impact assessment. Further research using panel data for several rounds and spanning longer intervals of intervention and adoption of IPM is worth consideration. There is a need to measure food security in other dimensions that are not considered in this study in order to provide a better understanding of the effect of IPM technology on food security from mango production.

\section{ACKNOWLEDGEMENTS}

The authors would like to acknowledge financial support from the UK Aid from the UK Government and the African Economic Research Consortium (AERC). International Centre of Insect Physiology and Ecology (icipe) also receives core funding from Swedish International Development Cooperation Agency (Sida), the Swiss Agency for Development and Cooperation (SDC), Federal Ministry for Economic Cooperation and Development (BMZ), Germany, and the Kenyan Government. The authors are also extremely indebted to the African Fruit Fly Programme (AFFP) of the icipe for field logistics support, farmers who voluntarily participated in the household surveys and the enumerators for their effort in data collection. An early version of this paper was presented at the $91^{\text {st }}$ Agricultural Economics Society Annual Conference in Dublin, Ireland and the authors would like to thank the participants for their insightful comments. 


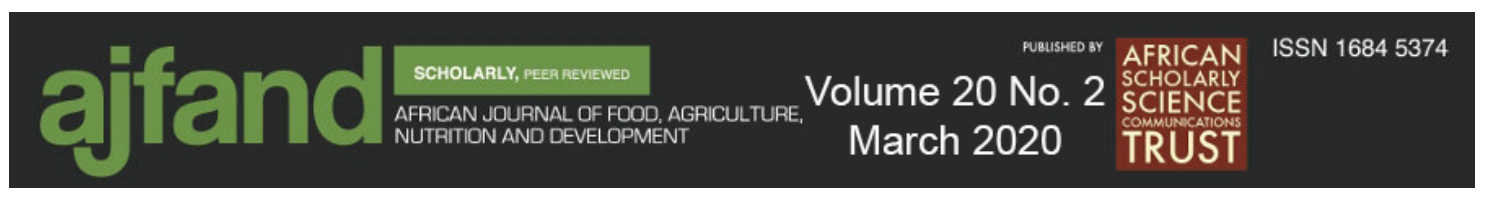

Table 1: Variables definition and hypothesized signs for determinants of food security

\begin{tabular}{|c|c|c|}
\hline Variable & Definition and measurement & $\begin{array}{l}\text { Expected } \\
\text { sign }\end{array}$ \\
\hline IPM & $\begin{array}{l}\text { Mango IPM control package treatment status (Dummy) } \\
1=\text { household in treatment group, } 0=\text { household in control group }\end{array}$ & + \\
\hline Time & $\begin{array}{l}\text { Time period survey was conducted (Dummy) } 0=\text { before intervention } \\
1=\text { After intervention }\end{array}$ & + \\
\hline IPM*Time & $\begin{array}{l}\text { Actual mango IPM intervention variable (Dummy) } 1=\text { only after } \\
\text { intervention if household applies the IPM package, } 0=\text { otherwise }\end{array}$ & + \\
\hline Age & Age of household head in years (Continuous) & + \\
\hline Age Squared & $\begin{array}{l}\text { Square of age of the household head } \\
\text { Continuous }\end{array}$ & + \\
\hline Education & $\begin{array}{l}\text { Household Head number of formal education } \\
\text { Continuous }\end{array}$ & + \\
\hline Gender & Gender of the household head (Dummy) $1=$ male $0=$ female & $+/-$ \\
\hline Household size & Number of persons in a household (Continuous) & $+/-$ \\
\hline $\begin{array}{l}\text { Farming } \\
\text { experience }\end{array}$ & Total number of years of experience in mango farming (Continuous) & + \\
\hline $\begin{array}{l}\text { Group } \\
\text { Membership }\end{array}$ & Whether a farmer belongs to a farmer group (Dummy) $1=$ yes $0=$ No. & + \\
\hline Extension & $\begin{array}{l}\text { Whether a farmer had any contact with an extension worker over the } \\
\text { last one year (Dummy) } 1=\text { Yes } 0=\text { No }\end{array}$ & + \\
\hline Asset wealth ${ }^{\mathrm{a}}$ & $\begin{array}{l}\text { Wealth category classification of the household (Categorical) } \\
2=\text { Wealthy } 1=\text { Moderate wealthy } 0=\text { Poor/not wealthy }\end{array}$ & + \\
\hline Market distance & Distance in walking hours to the nearest market (Continuous) & - \\
\hline Credit & $\begin{array}{l}\text { Whether a farmer acquired credit for mango production (Dummy) } \\
1=\text { Yes } 0=\text { No }\end{array}$ & - \\
\hline
\end{tabular}

Note: ${ }^{\mathrm{a}} 0=$ Poor/not wealthy used as the base in the analysis 


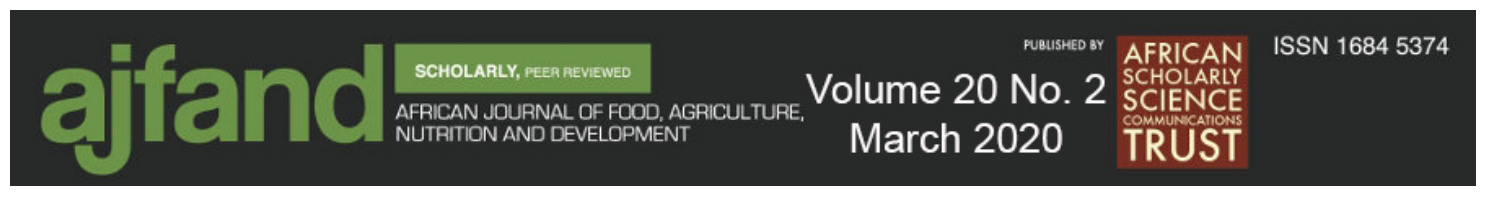

Table 2: Social-economic characteristics of sample households

\begin{tabular}{|c|c|c|c|c|c|}
\hline & \multicolumn{2}{|c|}{$\begin{array}{c}\text { IPM users } \\
\text { Mwala }(n=299)\end{array}$} & \multicolumn{2}{|c|}{$\begin{array}{c}\text { Non-IPM users } \\
\text { Kangundo }(\mathrm{n}=\mathbf{2 8 2})\end{array}$} & \multirow[t]{2}{*}{$\begin{array}{l}\text { Test of difference } \\
\text { in means (t-stat) }\end{array}$} \\
\hline & Mean & SD & Mean & SD & \\
\hline Age & 57.51 & 12.56 & 60.50 & 12.13 & $2.921 * * *$ \\
\hline Education & 8.58 & 3.94 & 10.16 & 3.88 & $4.881 * * *$ \\
\hline Gender & 0.86 & 0.35 & 0.89 & 0.32 & 1.089 \\
\hline Household size & 4.92 & 2.10 & 4.63 & 1.88 & $-1.783^{*}$ \\
\hline Farming experience & 11.26 & 9.40 & 8.52 & 6.97 & $-3.964 * * *$ \\
\hline Group membership & 0.31 & 0.47 & 0.24 & 0.43 & $-2.071 * *$ \\
\hline Extension & 0.24 & 0.43 & 0.11 & 0.32 & $-4.051 * * *$ \\
\hline Asset wealth & 0.43 & 0.66 & 0.45 & 0.71 & 0.272 \\
\hline Market distance & 4.96 & 5.11 & 10.48 & 7.56 & $10.37 * * *$ \\
\hline Credit & 4.68 & 21.16 & 1.42 & 11.85 & $-2.276^{* *}$ \\
\hline
\end{tabular}

Note: *significant at $10 \% * *$ significant at $5 \%$ and $* * *$ significant at $1 \%$; SD- Standard deviation

Source: Author's survey 


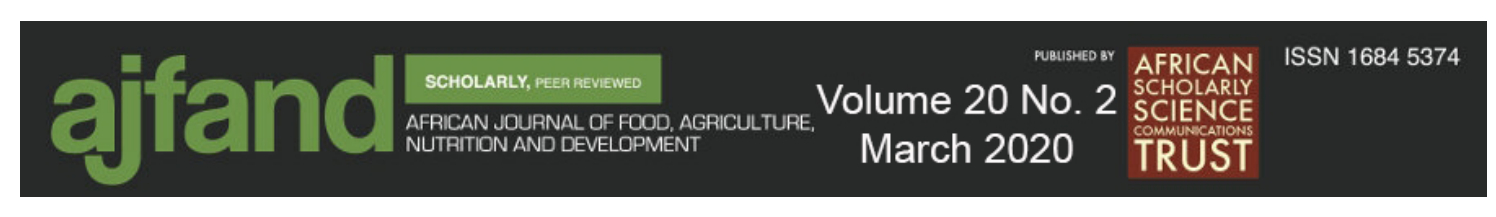

Table 3: Food security outcomes of IPM users and non-users

\begin{tabular}{|c|c|c|c|c|c|c|c|c|c|}
\hline & \multicolumn{3}{|c|}{ Baseline survey } & \multicolumn{3}{|c|}{ Follow-up survey } & \multicolumn{3}{|c|}{ Change (follow-up - Baseline) } \\
\hline & $\begin{array}{c}\text { IPM participants } \\
\text { (Mwala sub- } \\
\text { county) } \\
\mathrm{n}=299\end{array}$ & $\begin{array}{c}\text { IPM non- } \\
\text { participants } \\
\text { (Kangundo sub- } \\
\text { county) } \\
\text { n=282 }\end{array}$ & t-test & $\begin{array}{c}\text { IPM participants } \\
\text { (Mwala sub- } \\
\text { county) } \\
\text { n=299 }\end{array}$ & $\begin{array}{c}\text { IPM non- } \\
\text { participants } \\
\text { (Kangundo sub- } \\
\text { county) } \\
\mathrm{n}=282\end{array}$ & t-test & $\begin{array}{c}\text { IPM participants } \\
\text { (Mwala sub- } \\
\text { county) } \\
\mathrm{n}=289\end{array}$ & $\begin{array}{c}\text { IPM non- } \\
\text { participants } \\
\text { (Kangundo sub- } \\
\text { county) } \\
\text { n=277 }\end{array}$ & t-test \\
\hline $\begin{array}{l}\text { Per capita calorie } \\
\text { intake } \\
\text { (Kilocalories) }\end{array}$ & 2839.52 & 3006.52 & $0.010^{* *}$ & 2731.48 & 2843.22 & $0.098^{*}$ & -97.56 & -159.41 & 0.367 \\
\hline $\begin{array}{l}\text { Household dietary } \\
\text { diversity index } \\
\text { (HDDI) }\end{array}$ & 9.81 & 9.80 & 0.876 & 9.71 & 9.70 & 0.895 & -.10 & -.10 & 0.973 \\
\hline
\end{tabular}

Source: Author's survey 


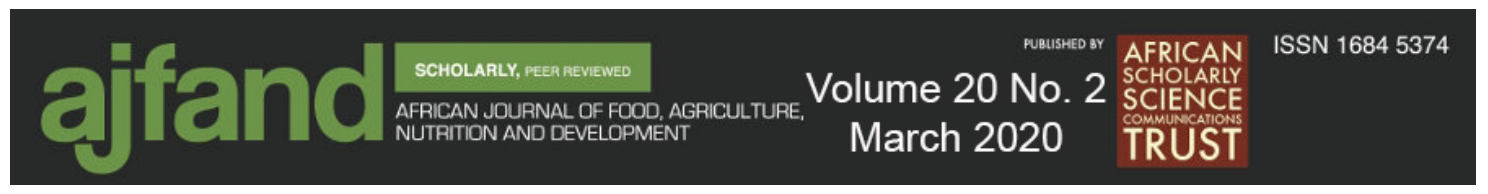

Table 4: Difference in Difference (DiD) estimate of average IPM technology effect on per capita calorie intake

\begin{tabular}{llcc}
\hline \multicolumn{1}{c}{ Survey Period } & $\begin{array}{c}\text { IPM } \\
\text { participants (I) }\end{array}$ & $\begin{array}{c}\text { IPM Non } \\
\text { participants } \\
\text { (C) }\end{array}$ & $\begin{array}{c}\text { Difference across } \\
\text { I\&C }\end{array}$ \\
\hline Follow up (2015) & 2731 & 2843 & -112 \\
Baseline (2014) & 2840 & 3007 & -167 \\
Difference across & -109 & -164 & 55 \\
time & & \\
Percentage change & $55 / 2840 * 100=1.93 \%$ & \\
\hline
\end{tabular}

Source: Author's survey 


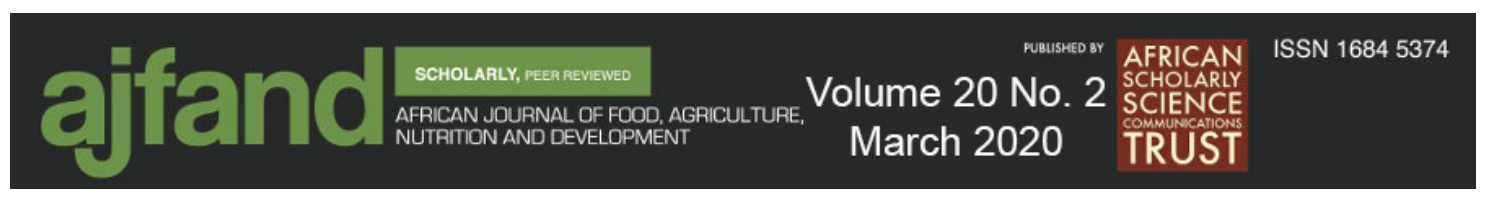

Table 5: DiD model estimates for the effect of Fruit fly IPM technology on Per Capita Calorie Intake

\begin{tabular}{|c|c|c|c|c|c|c|}
\hline & Uncondi & tional effect & & Conditic & ial effect & \\
\hline Variable & Coeff & $\begin{array}{l}\text { Semi } \\
\text { Robust } \\
\text { Standard } \\
\text { error }\end{array}$ & t-stat & Coeff & $\begin{array}{l}\text { Semi Robus } 1 \\
\text { Standard } \\
\text { error }\end{array}$ & t-stat \\
\hline $\operatorname{IPM}(\delta)$ & -167.00 & 78.65 & $-2.58 * *$ & -149.10 & 89.55 & $-1.66^{*}$ \\
\hline Time $(\gamma)$ & -160.46 & 41.16 & $\begin{array}{l}- \\
3.45 * * *\end{array}$ & -184.62 & 42.84 & $-4.31 * * *$ \\
\hline IPM*time $(\tau)$ & 60.15 & 57.42 & 0.94 & 96.79 & 58.37 & $1.66^{*}$ \\
\hline Age & & & & -6.99 & 19.37 & -0.36 \\
\hline Age squared & & & & 0.07 & 19.58 & 0.43 \\
\hline Gender & & & & 81.14 & 96.12 & 0.84 \\
\hline Household size & & & & -169.18 & 16.08 & $\begin{array}{l}- \\
10.52 * * *\end{array}$ \\
\hline Farming & & & & -1.07 & 2.11 & -0.51 \\
\hline Experience & & & & & & \\
\hline Group membership & & & & -40.00 & 54.36 & -0.74 \\
\hline Extension & & & & 154.91 & 62.82 & $2.47 * *$ \\
\hline $\begin{array}{l}\text { Moderately asset } \\
\text { wealthy }\end{array}$ & & & & 198.69 & 78.84 & $2.52 * *$ \\
\hline Asset Wealthy & & & & 269.80 & 104.79 & $2.57 * *$ \\
\hline Market Distance & & & & 12.89 & 4.96 & $2.60 * *$ \\
\hline Credit & & & & -125.85 & 124.09 & -1.01 \\
\hline Constant & 3006.52 & 45.64 & $\begin{array}{l}65.85 * * \\
*\end{array}$ & 3630.78 & 590.38 & $6.18^{* * *}$ \\
\hline $\mathrm{R}^{2}$ & 52 & & & 56 & & \\
\hline F value & 0.00 & & & 0.00 & & \\
\hline $\begin{array}{l}\text { Number of } \\
\text { observations }\end{array}$ & 1147 & & & & & \\
\hline
\end{tabular}

Notes: *significant at 10 percent, $* *$ at 5 percent and $* * *$ at 1 percent level

Source: Author's survey 


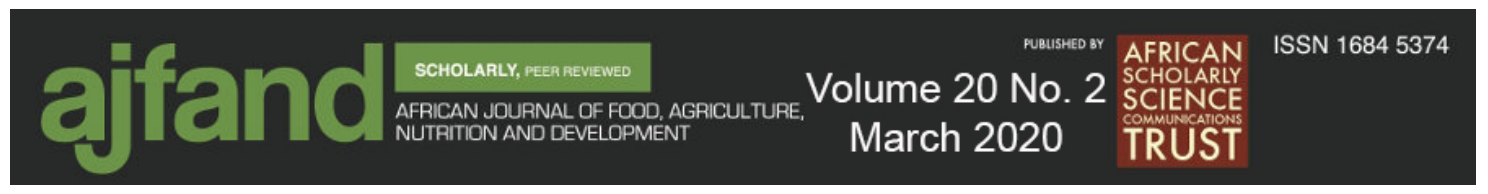

Table 6: Difference in Difference (DiD) estimate of average IPM technology effect on HDDI

\begin{tabular}{llll}
\hline \multicolumn{1}{c}{ Survey Period } & IPM participants(I) & $\begin{array}{c}\text { IPM Non } \\
\text { participants (C) }\end{array}$ & $\begin{array}{c}\text { Difference } \\
\text { across I\&C }\end{array}$ \\
\hline Follow up (2015) & 9.709 & 9.700 & +0.009 \\
Baseline (2014) & 9.806 & 9.798 & +0.008 \\
Difference across & -0.097 & -0.098 & +0.001 \\
time & & \\
Percentage change & $0.001 / 9.806^{*} 100=0.01 \%$ & \\
\hline
\end{tabular}

Source: Author's survey 


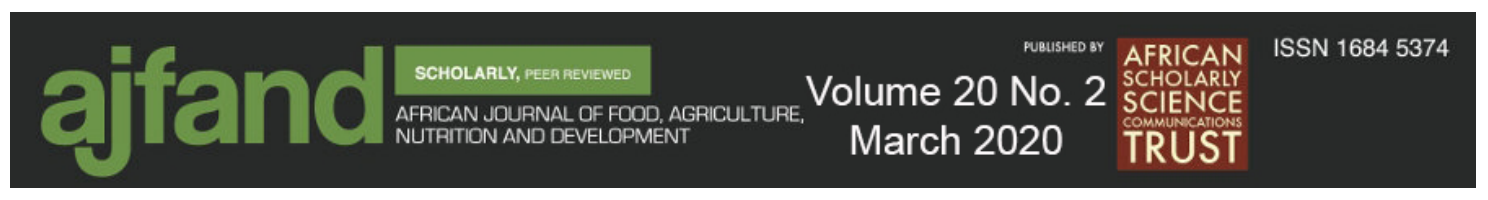

Table 7: DiD model estimates for the effect of Fruit fly IPM technology on HDDI

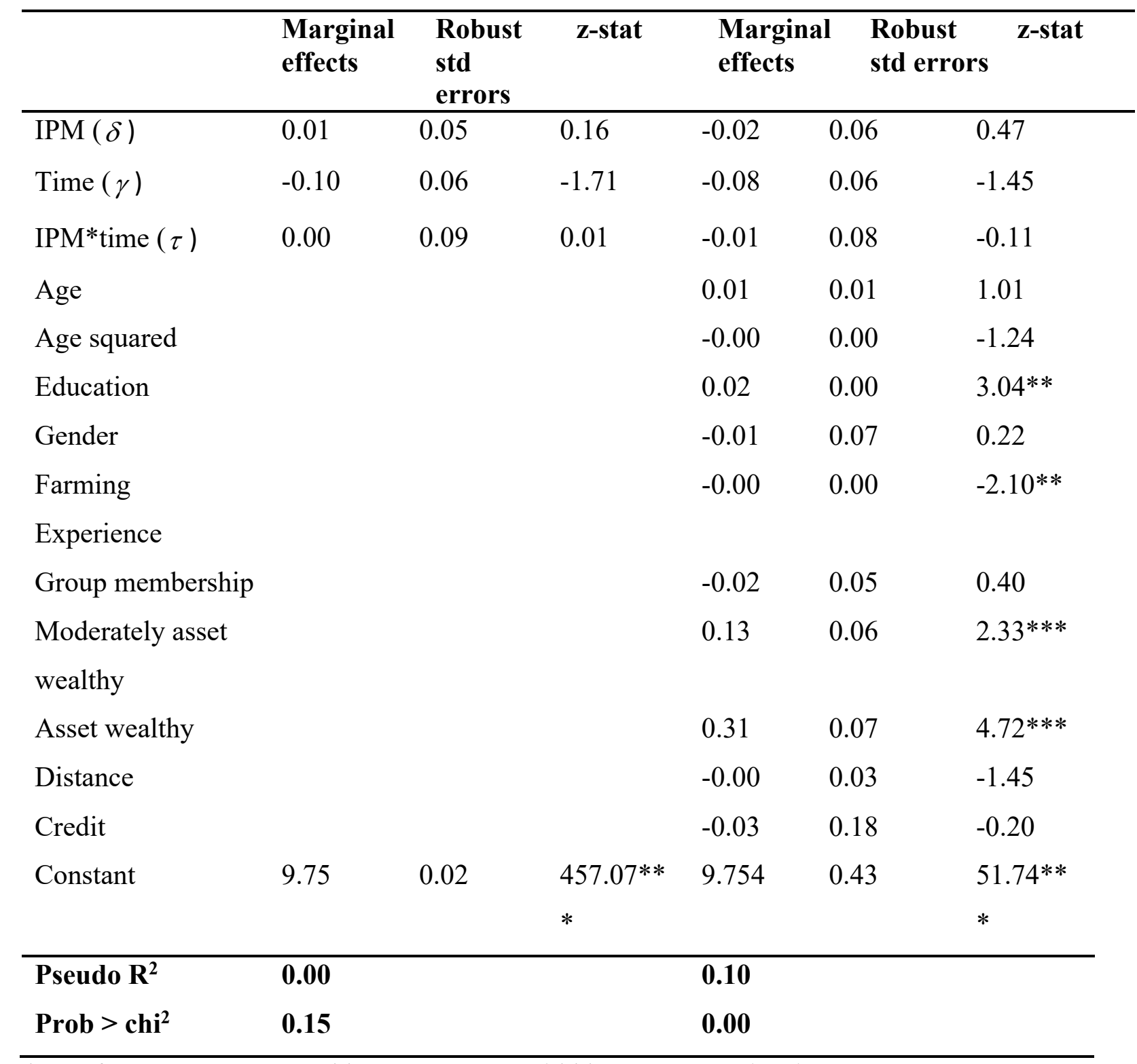

*significant at 10 percent, $* *$ at 5 percent and $* * *$ at 1 percent level

Source: Author's survey 


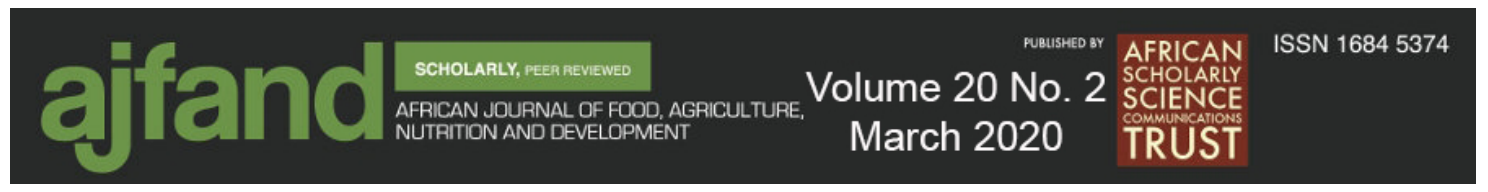

\section{REFERENCES}

1. Government of Kenya (GoK). Kenya's LAPSSET Corridor Mango Production Investment Opportunity. Government Printers, Nairobi, 2012.

2. Horticultural Crops Development Authority (HCDA). National Horticulture Validated report 2013. 2014.

3. Government of Kenya (GoK). Economic Review of Agriculture [ERA]. Ministry of Agriculture. Central Planning and Project Monitoring Unit. Government printers, Nairobi, 2015.

4. Horticultural Crops Development Authority (HCDA). National Horticulture Validated Report 2009. 2010.

5. Irungu J. Contribution of horticulture to food security in Kenya. All Afr. Hort. Cong. 2009; 911: 27-32.

6. Ekesi S, Chabi-Olaye A, Subramanian S and C Borgemeister Horticultural pest management and the African economy: successes, challenges and opportunities in a changing global environment. All Afr. Hort. Cong. 2011; 911: 165-183.

7. Ravry C Situation in Botswana, Kenya, Mozambique, Namibia, Zambia and Zimbabwe. In Fighting Fruit and Vegetable Flies Regionally in West Africa Information Letter, 2008:2.

8. Amata R, Otipa M, Waiganjo M, Wabule M, Thuranira E, Erbaugh $M$ and $S$ Miller Incidence, prevalence and severity of passion fruit fungal diseases in major production regions of Kenya. J App. Biosci. 2009; 20: 1146-1152.

9. Macharia I N, Mithöfer $\mathbf{M}$ and $\mathbf{H}$ Waibel Potential environmental impacts of pesticides use in the vegetable sub-sector in Kenya. Afr J Hort. Sci. 2009; 2:138151.

10. Ekesi S and MK Billah A Field Guide to the Management of Economically Important Tephritid Fruit Flies in Africa, ICIPE Science Press, Nairobi, 2007. ISBN 929064209.

11. Korir JK, Affognon HD, Ritho CN, Kingori WS, Irungu P, Mohamed SA and S Ekesi Grower adoption of an integrated pest management package for management of mango-infesting fruit flies (Diptera: Tephritidae) in Embu, Kenya. Int J Trop Ins Sci. 2015; 35(2): 80-89.

12. Muriithi BW, Affognon HD, Diiro GM, Kingori SW, Tanga CM, Nderitu PW, Mohamed SA and S Ekesi Impact assessment of Integrated Pest Management (IPM) strategy for suppression of mango-infesting fruit flies in Kenya. Crop Prot. 2016; 81:20-29. 


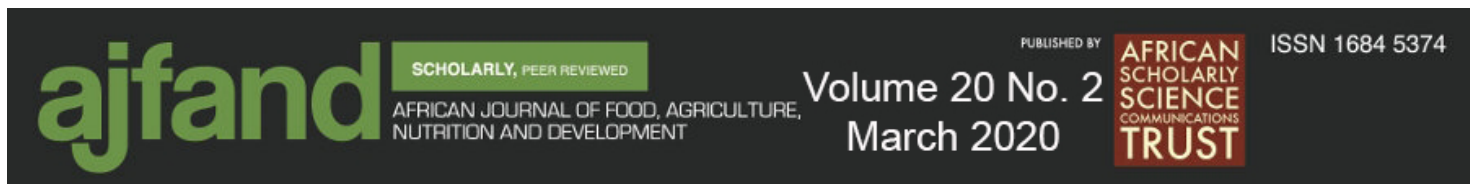

13. Ekesi S, Mohamed S and CM Tanga Comparison of food-based attractants for Bactrocera invadens (Diptera: Tephritidae) and evaluation of mazofermespinosad bait spray for field suppression in mango. J Econ Entom. 2014;107: 299-309.

14. Klungness LM, Jang EB, Mau RF, Vargas RI, Sugano JS and E Fujitani New sanitation techniques for controlling tephritid fruit flies (Diptera: Tephritidae) in Hawaii. J App Sci. Env Manag. 2005; 9(2): 5-14.

15. Asfaw S, Kassie M, Simtowe F and L Leslie Lipper Poverty Reduction Effects of Agricultural Technology Adoption: A Micro-evidence from Rural Tanzania. $J$ Dev Stud. 2012; 48(9): 1288-1305.

16. Mulugeta $\mathbf{T}$ and $\mathbf{B}$ Hundie Impacts of Adoption of Improved Wheat Technologies on Households' Food Consumption in Southeastern Ethiopia. (International Association of Agricultural Economists Conference, August 18-24, 2012), Foz do Iguacu, Brazil, 2012.

17. Kibira M, Affognon H, Njehia B, Muriithi B, Mohamed S and S Ekesi Economic evaluation of integrated management of fruit fly in mango production in Embu County, Kenya. Afr J Agric Res Econ. 2015;10: 311-343.

18. Fernandez-Cornejo $\mathbf{J}$ Environmental and economic consequences of technology adoption: IPM in viticulture. Agric Econ. 1998; 18(2): 145-155.

19. Tambo JA and T Wünscher Farmer-led innovations and rural household welfare: Evidence from Ghana. J Rural Stud. 2017; 55: 263-274.

20. von Braun $\mathbf{J}$ Effects of technological change in agriculture on food consumption and nutrition: rice in a West African setting. World Dev. 1988; 16: 1083-1098.

21. Pandey VL, Dev SM and U Jayachandran Impact of agricultural interventions on the nutritional status in South Asia: A review. Food Pol. 2016; 62: 28-40.

22. Bartlett JE, Kotrlik JW and CC Higgins Organizational Research: Determining Appropriate Sample Size in Survey Research. Infor Tech Learn Perform J. 2001; 19(1): 43-50.

23. Food and Agriculture Organization (FAO). World Food Summit Plan of Action. Rome, 1996.

24. Gross RW Schultink and AA Kielmann Community Nutrition: Definition and Approaches in M. Sadler, J.J. Strain and B. Caballero (Eds.) (1999), Encyclopedia of Human Nutrition, Academic Press Ltd., London, U.K. 1999: 433-441.

25. Babatunde RO, Omotosho OA and OS Sholotan Factors influencing food security status of rural farming households in North Central Nigeria. Agric J. 2007; 2(3): $351-357$. 


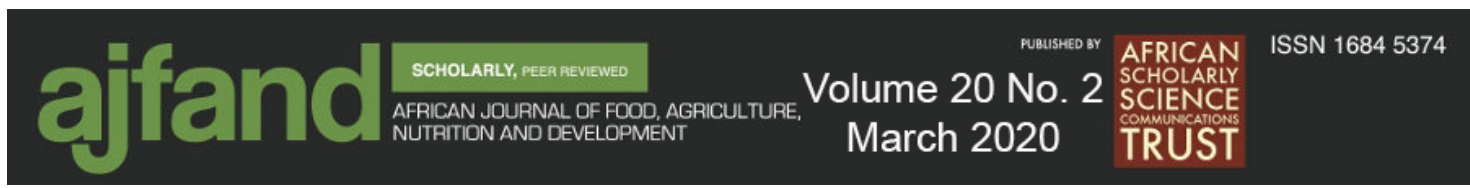

26. Pinstrup-Andersen P Food security: definition and measurement. Food Sec. 2009; 1(1):5-7.

27. Kassie M, Ndiritu $\mathbf{S W}$ and $\mathbf{J}$ Stage What determines gender inequality in household food security in Kenya? Application of exogenous switching treatment regression. World Dev. 2013; 56: 153-171.

28. Swindale A and $\mathbf{P}$ Bilinsky Household dietary diversity score (HDDS) for measurement of household food access: indicator guide. Washington, DC: Food and Nutrition Technical Assistance Project, Academy for Educational Development. 2006.

29. Hoddinott $\mathbf{J}$ and $\mathbf{Y}$ Yohannes Dietary diversity as a food security indicator. Food consumption and nutrition division discussion paper. 2002; 136(136).

30. Glewwe $\mathbf{P}$ and $\mathbf{H}$ Jacoby Recommendations forcollecting panel data. In M. Grosh, \& P. Glewwe(Eds.), Designing household survey questionnaires for developing countries: lessons from 15 years of theLiving Standards Measurement Study. New York: Oxford University Press for the World Bank, 2000.

31. Ravallion M Evaluating anti-poverty programs. Paper Prepared for the Handbook of agricultural economics (Vol 4), ed. R. Evenson and TP Schultz. North-Holland, the Netherlands Elsevier, 2005.

32. Amaza P, Abdoulaye T, Kwaghe $\mathbf{P}$ and A Tegbaru Changes in household food security and poverty status in PROSAB area of Southern Borno State, Nigeria. International Institute of Tropical Agriculture (IITA) Promoting Sustainable Agriculture in Borno State (PROSAB). IITA, Nigeria, 2009.

33. Iyangbe $\mathbf{C}$ and $\mathbf{S}$ Orewa Determinants of daily protein intake among rural and low-income urban households in Nigeria. Amer-Eur J Sci Res. 2009; 4:290-301.

34. Feleke ST, Kilmer RL and CH Gladwin Determinants of food security in Southern Ethiopia at the household level. Agric Econ. 2005; 33(3): 351-363.

35. Greene WH Fixed and random effects models for count data. NYU Working Paper No. EC-07-16. 2007.

36. Wooldridge JM Introductory Econometrics. A Modern Approach. 5th ed. Mason, OH: South-Western Cengage Learning Cengage, 2013.

37. Goshu D, Kassa $\mathbf{B}$ and $\mathbf{M}$ Ketema. Is food security enhanced by agricultural technologies in rural Ethiopia? J Agric Res Econ. 2013; 8(1): 58-68. 